\section{Irreducible Posterior Dislocation of the Elbow}

Brit. med. F., 1967, 3, 659

All published reports on posterior dislocation of the elbow are concerned with old dislocations (Vangorder, 1932 ; Allende and Freytes, 1944), disclocations associated with fracture of the medial epicondyle with displacement into the joint (Roberts, 1934 ; Outland and Hanlon, 1938 ; Patrick, 1946 ; Smith, 1950 ; Purser, 1954), dislocation associated with rupture of the brachial artery (Spear and Janes, 1951 ; Henderson and Robertson, 1952), dislocation complicated by ulnar nerve injury (Outland and Hanlon, 1938), and recurrent dislocations of the elbow (Milch, 1936 ; Reichenheim, 1947 ; Wainwright, 1947 ; Kapel, 1951 ; King, 1953 ; Spring, 1953 ; Osborne and Cotterill, 1966). However, a search of the literature from the English-speaking world has not revealed any reported case where there was failure to reduce an uncomplicated posterior dislocation of the elbow by manipulation under anaesthesia soon after injury. This must be extremely uncommon. This report describes stuch a case.

\section{Case Report}

A girl aged 7 years was seen with an injury to her left elbow after a fall on her outstretched hand. On examination the elbow was deformed and there was no bruising or swelling around that joint. There was no nerve or vascular injury. $X$-ray examination of the elbow showed posterior dislocation without fracture.

Three hours after the injury the elbow was manipulated under general anaesthesia, but the dislocation could not be reduced despite a further attempt later. Even at this stage the elbow did not show any bruising or swelling. Because of the absence of bruising and swelling an old dislocation of the elbow was considered, but the patient was very intelligent and maintained that the left elbow was normal before the fall. Open reduction was undertaken the following day.

Operation.-Initially, the elbow was explored through a medial vertical incision. There was no bruising in the soft tissues. The medial ligament and the medial epicondyle were normal. A posterolateral incision was made and the head of the radius was found dislocated through a small buttonhole tear in the posterolateral capsule of the joint. The proximal ulna was found dislocated posteriorly without any tear in the capsule. On attempting reduction the buttonhole in the capsule tightened around the narrow portion of the neck of the radius and prevented reduction. After enlarging the buttonhole the dislocation was reduced quite easily. The orbiculan ligament was found intact.

Postoperative progress was normal and the elbow was immobilized for three weeks. Two months later the eloow movements were satisfactory except for the last few degrees of extension.

\section{COMMENT}

It is quite evident in this case that closed reduction failed because the head of the radius had passed through a small tear in the posterolateral capsule and the buttonhole effect tightened around the narrow portion of the neck of the radius. When traction was applied in the line of the deformity the buttonhole tightened and prevented reduction of the dislocation. Once the buttonhole was enlarged the reduction was very easy.

Another interesting feature in this case is that there was no bruising or swelling - a feature sufficient to make one consider the possibility of an old injury. One would expect some bruising and swelling on the medial side of the joint in a recent dislocation of the elbow. In this case the medial ligament would have been stretched and not torn. The torn blood vessels in the buttonhole tear in the capsule did not bleed, probably because the vessels were compressed by the neck of the radius or because displacement was so minimal.

I wish to thank Mr. E. J. Hargadon for permission to publish this case and for his helpful criticism.

\section{A. Devadoss, M.B., B.S., F.R.C.S.ED., F.R.C.S.GLASG., Park Hospital, Davyhulme Manchester. Present address: Orthopaedic Unit, Sefton General Hospital, Liverpool} 15.

REFERENCES

Allende, G., and Freytes, M. (1944). F. Bone ft Surg., 26, 691. Henderson, R. S., and Robertson, I. M. (1952). Ibid., 34B, 636. Kapel, O.'(1951). Ibid., 33A, 707.

King, T. (1953). Ibid., 35B, 50.

Milch, H. (1936). Ibid. 18, 777

Osborne G., and Cotterill, P. (1966). Ibid., 48B, 340.

Outland, T., and Hanlon, C. R. (1938). Ibid., 20, 750

Patrick, J. (1946). Ibid., 28, 143

Patrick, J. (1946). Ibid., 28, 143.

Purser, D. W. (1954) ig47). Brit. 7 . Surg., 35, 201.

Reichenheim, P. P. (1947). Brit. F. Sur

Smith, F. M. (1950). F. Amer. med. Ass., 142, 396.

Spear, H. C., and Janes, J. M. (1951). ₹. Bone $f_{t}$ Surg., 33A, 889.

Spring, W. E. (1953). Ibid., 35B, 55 .

Vangorder, G. W. (1932). Ibid., 14, 127.

Wainwright, D. (1947). Proc. roy. Soc. Med. (Section of Orthopaedics), 40, 885 .

\section{Human Infection with a Tapeworm, Bertiella sp., probably of African origin}

Brit. med. F., 1967, 3, 659-660

Proglottides of a tapeworm were passed intermittently for six months in the faeces of a British boy aged 6 who was otherwise well and had no complaint of bowel disturbance. He had lived in Aden for the previous two years. The proglottides proved to be terminal segments of Bertiella sp. Identification to species was not possible. The boy was successfully treated with niclosamide (Yomesan).

Bertiella is normally a parasite of monkeys. On further inquiry it was found that nearly two years previously the boy had spent a fortnight's holiday in Mombasa, East Africa, where he had close contact with monkeys; these were thought to be of the rhesus type and were tame enough to be fed by hand.

The life history of Bertiella studeri (Blanchard, 1891), which is the principal species of the Eastern Hemisphere, was eluci- dated by Stunkard (1940); he fed eggs of the tapeworm experimentally to various free-living mites and later found cysticercoids (the infective stage for the final, definitive host) in the

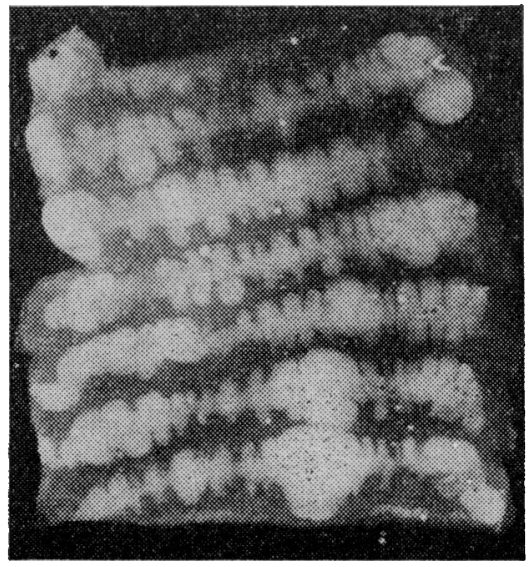

Segments of Berticlla sp. tapeworm. (x 5.) 
body cavity of some of the mites. Presumably, human infection results from the accidental ingestion of infected mites.

This is the twenty-fifth report of human infection with bertiella. Geographically, these reports are mainly from the Eastern Hemisphere-namely, Mauritius (4), India (8), Sumatra (1), Java (2), Borneo (1), Philippines (1), Singapore (1), East Africa (1). In the Western Hemisphere it has been reported once from Cuba, St. Kitts (West Indies), Brazil, Argentina, and Paraguay. The present case is of interest in that the infection was probably acquired in Africa, whence only one case has previously been recorded (Buckley and Fairley, 1950), and in that from the available evidence the boy had probably harboured the worm for about two years.

The subject of bertiella infection to man has been recently reviewed by D'Alessandro, Beaver, and Pallares (1963).

\section{Self-poisoning with Digoxin: Successful Treatment with Atropine}

\section{Brit. med. F., 1967, 3, 660-661}

Self-poisoning with digitalis is uncommon. Lethal doses are massive (McGuire and Richards, 1936; Bergy et al., 1957 ; Johnston and Price, 1960), and death is more likely to follow the ingestion of digitoxin than the more rapidly excreted digoxin. Recovery after very large doses of digoxin (Bernstein et al., 1959) and digitoxin (Bergy et al., 1957 ; Knowles, 1959) has been reported, and it is apparent that survival is more likely when the myocardium is healthy.

\section{CAse Report}

A housewife aged 52 with a long history of depression started taking digoxin in 1961 for lone atrial fibrillation. At 11 a.m. on 18 October 1965 she took $6.25 \mathrm{mg}$. of digoxin. On admission to another hospital the pulse rate was 40 a minute and the blood pressure $90 / 40 \mathrm{~mm}$. $\mathrm{Hg}$; vomiting and diarrhoea decreased after chlorpromazine (100 mg. intramuscularly). On 19 October the pulse rate was $22-25$, and she was transferred to the London Chest Hospital.

She was drowsy and pale, with cold extremities. The pulse was regular at 15, and the blood pressure 120/60. There was slight hepatomegaly, but no other evidence of congestive cardiac failure. She had profuse cold sweats. An electrocardiogram (see Fig., A) showed no atrial activity; the ventricular rhythm was regular, with normal QRS complexes. Serum potassium was $7.9 \mathrm{mEq} / 1$. and blood urea $61 \mathrm{mg} . / 100 \mathrm{ml}$.

While preparations were being made to insert an electrode pacemaker catheter it was decided to try the effect of atropine. Atropine (0.6 mg.) was given intravenously ; the pulse rose to $60 / \mathrm{min}$. within 20 minutes, but then slowed to $36 / \mathrm{min}$. during the next 20 minutes. Atropine $(0.6 \mathrm{mg}$. intravenously) was repeated, and the rate increased to 72. The electrocardiogram (see Fig., B) showed sinus rhythm, with low-voltage $\mathrm{P}$ waves and constant long $\mathrm{P}-\mathrm{R}$ interval $(0.24 \mathrm{sec}$.). Whenever the heart rate fell below 50 , atropine $(0.6 \mathrm{mg}$.) was given intramuscularly; she needed an injection about every five hours for the first 36 hours. During this time the electrocardiogram showed an irregular bradycardia, with variable long $P-R$ interval $(0.24-0.30$ sec.), and variable $P$ wave morphology (see Fig., $C$ ); one tracing after atropine showed atrioventricular dissociation (see Fig., D). On 22 October she reverted to atrial fibrillation, with irregular ventricular response (see Fig., E) and was put back on digoxin.

On admission she had been anuric for over 24 hours. An intravenous drip ( $5 \%$ dextrose) was started, with added sodium bicarbonate; $20 \%$ mannitol was also given (total $300 \mathrm{ml}$. in 14 hours), and urine flow was re-established within half an hour. After an initial rise to $150 \mathrm{mg} . / 100 \mathrm{ml}$. the blood urea rapidly fell to normal ; the serum potassium also fell, to $4.2 \mathrm{mEq} / \mathrm{l}$., and potassium by mouth was started after 18 hours.
We are indebted to Mr. S. Nicholson for the preparation of the specimen and to Dr. M. R. Thomas for the photograph.

C. D. Thompson, M.B., B.CH., General Practitioner.

C. H. JELLARD, B.M., F.C.PATH., DIP.BACT., Director, Public Health Laboratory, Plymouth.

J. J. C. BUCKLEY, D.SC.,

Professor of Helminihology, London School of Hygiene and Tropical Medicine.

\section{REFERENCES}

D'Alessandro, B., Beaver, P. C., and Pallares, R. M. (1963). Amer. 7. trop. Med. Hyg., 12, 193.

Blanchard R. (1891) Miém. Soc. zool. Fr., 4, 186.

Buckley, J. J. C., and Faurley, N. H. (1950). Trans. roy. Soc. trop. Med. Hyg., 44, 2.

Stunkard, H. W. (1940). Amer. F. trop. Med., 20, 305.

She rapidly became more responsive, but remained seriously depressed, and was discharged for further psychiatric treatment after 10 days.

Liver-function tests initially gave abnormal results (21 October : S.G.O.T. 130 units/ml.; S.G.P.T. more than 160 units/ml. 27 October: sulphobromophthalein excretion test: $47 \%$ retention at 25 minutes, and $30 \%$ retention at 45 minutes) but later returned to normal.

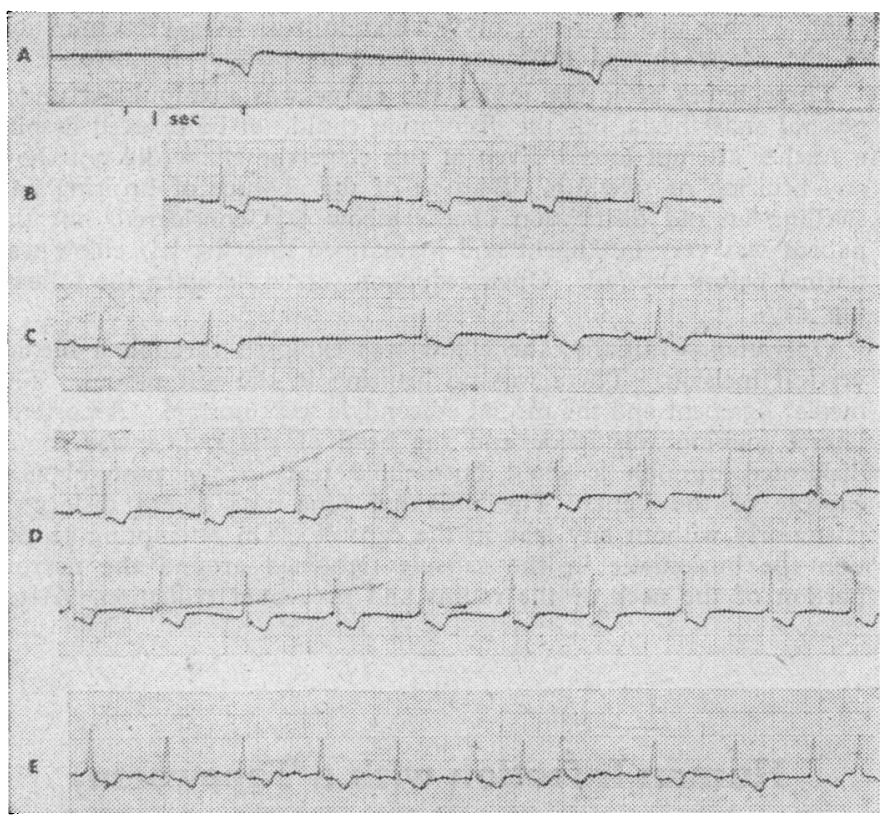

Serial electrocardiograms (all lead II). A, 19 October, before treatment : sinus arrest; extreme nudal bradycardia. B, 19 October, af ter intravenous atropine: sinus rhythm; low-voltage $\mathrm{P}$ waves; long P-R interval. C, 20
October: wandering pacemaker. D, 20 October, af ter atropine: two consecutive strips showing aurioventricular dissociation. E, 22 October: atrial fibrillation.

\section{Discussion}

The toxic effects of digitalis on the heart have been well reviewed by Burwell and Hendrix (1950), Lown and Levine (1954), Schott (1964), and Dubnow and Burchell (1965). A regular rhythm may occur in the presence of atrial fibrillation as a result of digitalis-induced complete heart block, when the ventricles are controlled by a pacemaker in the main bundle or atrioventricular node below the level of the block; a nodal rhythm may also be associated with atrioventricular dissociation. Sinuatrial block, "wandering pacemaker," and sinus arrest are rare, but were reported by Burwell and Hendrix (1950), and by Bernstein et al. (1959) and Knowles (1959) in their cases of massive overdose. In our patient there was atrial 